\title{
TESTE DE MICRONÚCLEOS COMO FORMA DE INCLUSÃO DOS PACIENTES COM DOENÇAS COGNITIVAS NOS SERVIÇOS DE SAÚDE
}

\author{
Isabela Soares Uchôa ${ }^{1}$ - UNIFSA \\ Francisco Ariel Paz Santos Freitas ${ }^{2}$ - UNIFSA \\ Matheus Fernandes de Castro ${ }^{3}$ - UNIFSA \\ Suzanne Tatianne Teixeira do Nascimento ${ }^{4}$ - UNIFSA \\ Maria do Amparo Veloso Magalhães ${ }^{5}$ - UNIFSA
}

\section{RESUMO}

A cognição envolve toda esfera do funcionamento mental e implica habilidade de sentir, pensar, perceber, lembrar, raciocinar, formar estruturas complexas de pensamentos e a capacidade de produzir respostas às solicitações e estímulos externos. Pacientes que possuem doenças neurodegenerativas podem com o tempo apresentar declínio funcional, perdendo qualidade de vida, já que, ficam limitados a desenvolver as atividades da vida diárias (AVD). Desta forma, a aplicação do teste de micronúcleos (MN), utilizando células esfoliadas da cavidade bucal é amplamente usada no biomonitoramento de lesões orais pré-cancerígenas, levando em consideração que a cavidade oral pode refletir a saúde dos indivíduos, porque a mucosa sobrejacente pode apresentar provas ao nível microscópico e alterações macroscópicas indicativas de doença local ou sistêmica, e que esses pacientes já tendem a apresentar problemas de saúde orais mais progressivos, incluindo úlceras linguais, xerostomia, cárie coronária, hiperplasia da mucosa, entre outros, decorrentes da falta do autocuidado. A presente pesquisa busca determinar à instabilidade cromossômica e morte celular em células da mucosa bucal em pacientes com deficiência cognitiva atendidos em serviço de referência odontológica a pessoa com deficiência intelectual e autismo em Teresina-PI.

Palavras-Chave: Instabilidade Genômica. Micronúcleo. Doenças Crônicas.

\section{INTRODUÇÃO}

A cognição é o ato ou processo da aquisição do conhecimento que se dá através da percepção, da atenção, associação, memória, raciocínio, juízo, imaginação, pensamento e linguagem (FERREIRA, 2010). É o conjunto dos processos mentais usados no pensamento na classificação, reconhecimento e compreensão para o julgamento através do raciocínio para o aprendizado de determinados sistemas e soluções de problemas. Alguns fatores como socioeconômico, psicológico e de saúde, podem contribuir para o declínio gradual das funções cognitivas (GURIAN et al., 2012).

${ }^{1}$ Graduanda em Bacharelado de Enfermagem pelo Centro Universitário Santo Agostinho. Email: risabela927@gmail.com

${ }^{2}$ Graduando em Bacharelado de Enfermagem pelo Centro Universitário Santo Agostinho. Email: arielpazsantos@hotmail.com

${ }^{3}$ Graduando em Bacharelado de Enfermagem pelo Centro Universitário Santo Agostinho. Email: matheus.feca@gmail.com

${ }^{4}$ Bacharel em Serviço Social pelo Centro Universitário Santo Agostinho. Email: suzzannytatianne@hotmail.com

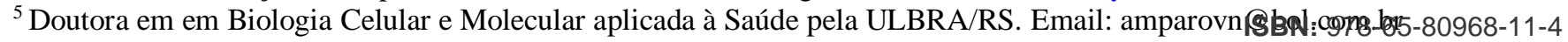


Segundo os autores supracitados, as modificações e os déficits causados pela perda na cognição acarretam consequências diretas sobre a qualidade de vida das pessoas, podendo levar ao declínio funcional, com diminuição e/ou perdas das habilidades para o desenvolvimento das atividades da vida diárias (AVD). Sabe-se que tanto as doenças físicas como as mentais podem levar à perda da independência e autonomia, sendo fatores de risco importantes para a mortalidade

Pessoas com deficiência cognitiva, além de todas as suas limitações, também têm problemas de saúde oral mais rapidamente progressivos, incluindo úlceras linguais, hiperplasia da mucosa, estomatite, má higiene oral, xerostomia, pior condição periodontal e mais cárie coronária e radicular (HERRERA et al., 2015).

Dessa forma, a assistência ao paciente deficiente, que envolve um conjunto de áreas afins (fisioterapia, psicologia, fonoaudiologia, neurologia, odontologia, enfermagem, terapia ocupacional, entre outras), precisa ser incentivada com a finalidade de somar esforços e recursos para que o trabalho aconteça de forma integrada, tendo como objetivo final o bem-estar do paciente. Ainda, o problema da pessoa com deficiência deve ser entendido e analisado, não somente como uma atribuição do Estado, mas também de toda Comunidade, que deve estar ciente desta problemática e sensível a ela, de modo a participar ativamente e contribuir para possíveis soluções dos inúmeros problemas enfrentados por esses indivíduos (ANDERS e DAVIS, 2010)

Há, contudo, uma relutância para a realização do atendimento odontológico de pacientes deficientes entre os profissionais da área que pode ser atribuída à falta de conhecimentos e treinamentos adequados; falta de sensibilidade e de confiança; além de remuneração inadequada e a crença de que são necessários equipamentos especiais e facilidades para que o tratamento seja realizado (OLIVEIRA et.al., 2008) (O'KEEFE, 2010).

Esses aspectos são agravados quando associados aos problemas de ansiedade e apreensão dos pais, baixa prioridade, devido a numerosos outros problemas presentes na rotina diária, dificuldade dos deficientes mais graves de expressar seu problema dentário, dificuldades de transporte, de acesso (falta de construções arquitetônicas adaptadas), altos custos do tratamento, além da discrepância de opiniões entre os cirurgiões-dentistas e pais quanto à necessidade ou não do tratamento (RAPALO et.al., 2010) (IDAIRA et.al., 2008). 
A pessoa deficiente apresenta inúmeros problemas decorrentes de diferentes bases etiológicas com a probabilidade de ocorrência de distúrbios de comunicação, locomoção e sentido, sendo constantes os problemas de ordem médica e odontológica, que comprometem, sobremaneira, seu bem-estar. Esta realidade tornou premente a necessidade da atuação de uma equipe multiprofissional integrada e especializada (RAPALO et.al., 2010) (IDAIRA et.al., 2008).

O Serviço de Referência Odontológica à Pessoa com Deficiência Intelectual e Autismo, implantado no dia 27 de abril de 2017, atende uma média de 20 pacientes por mês, com deficiência cognitiva e está localizado no Hospital Dirceu Arcoverde da Polícia Militar do Piauí, na cidade de Teresina, Piauí, que é um Hospital especializado no atendimento à Assistência MédicoHospitalar, tendo como principal finalidade prevenir doenças, promover a saúde, estimular a educação e desenvolver pesquisa.

Portanto, objetiva-se caracterizar a presença de alterações como apresentar a pesquisa que está sendo desenvolvida a qual caracterizará a presença de alterações cromossômicas através do teste de $\mathrm{MN}$ na mucosa oral de pacientes com deficiente cognitiva. A fim de descrever as alterações sofridas por estas células, e oferecer oportunidades para diagnóstico precoce, aferição de evolução de tratamentos no que diz respeito à modulação genética após terapia antitumoral, além de servir como parâmetro de orientação e aconselhamento de mudança de hábitos, e ser um procedimento simples, eficaz e realizado a baixo custo (FREITA et al., 2014).

\section{METODOLOGIA}

O trabalho trata-se de um estudo qualitativo e quantitativo amostral e que visa à coleta, e a análise de dados e materiais biológicos coletados no Serviço de referência odontológica à pessoa com deficiência intelectual e autismo do Hospital Dirceu Arcoverde da Polícia Militar do Piauí, na cidade de Teresina, Piauí.

Farão parte da população de estudo todos os 30 indivíduos sem restrição de gênero, com registro de atendimento de maio de 2017 a janeiro de 2019, que retornarão para reavaliação oral de rotina. Um grupo controle pareado de pacientes normosistêmicos também será abordado ( $\mathrm{n}=$ 30), após a assinatura do Termo de Consentimento Livre e Esclarecido (TCLE) e / ou Termo de Assentimento Livre e Esclarecido (TALE).

Para coleta de dados será utilizado um questionário adaptado de CARRANO; NATARAJAM, 1988, detalhado e organizado, com perguntas abertas e fechadas, que será respondido pelo 


\section{CONQGESSOOCIENCIAESOCIEDADE

responsável pelo paciente com deficiência cognitiva, um questionário que abordará detalhes da patologia e um questionário que buscará dados sobre as percepções do responsável e/ou cuidador responsável pelo deficiente cognitivo, atendendo aos objetivos propostos na pesquisa. As perguntas têm por base a verificação os hábitos e rotina do indivíduo entrevistados para que assim seja possível analisar as condições de vulnerabilidade exposição aos riscos de formação de micronúcleos em célula da mucosa oral.

A coleta do material biológico será realizada por meio de uma escova citológica (cytobrush) retirando-se a amostra do epitélio jugal direito e esquerdo, após um enxágue bucal realizado com água com a função de retirar material bruto que pudesse constituir um artefato no momento da análise microscópica (THOMAS ET al., 2009). As células de todos os indivíduos da amostra serão coletadas de sítios da mucosa oral, ausente de ulcerações e outras lesões visíveis. Serão excluídos os indivíduos que apresentem doenças bucais visíveis que possam vir a comprometer os resultados do estudo e evitar riscos possíveis de agravamentos das lesões preexistentes. As amostras coletadas serão depositadas e transportadas em tubos eppendorf de $15 \mathrm{~mL}$ contendo a solução tampão Tris- $\mathrm{HCl}$ pH 7,0 (0,01 M Tris- $\mathrm{HCl}$ (Merck), 0,1 M EDTA tetrassódico (Vetec), 0,02 M cloreto (Merck)) e enviadas para o laboratório, para serem processadas.

\section{ANÁLISE CRÍTICA}

A aplicação do Teste de Micronúcleos (MN) como já citado é uma técnica muito simples, eficaz, rápida e que não gera nenhum trauma nos pacientes. Com base no apresentado e em relação à pesquisa realizada até então, observou-se a importância de incluir a aplicação do teste de MN nos pacientes com deficiência cognitiva, a fim de verificar a existência de alterações celulares na mucosa oral, para correlacionar os resultados obtidos com a patologia apresentada por cada voluntário da pesquisa, o que norteará medidas preventivas mais eficazes especialmente quanto ao câncer de boca (UCHÔA et al., 2019).

Pessoas com deficiência cognitiva possuem capacidade de concentração e de percepção muito particulares. A limpeza da boca torna-se um desafio, uma vez que o acesso à cavidade oral para que haja a higienização diária é uma atividade na maioria das vezes ineficaz ou inexistente, muitos dos pacientes não aceitam de forma passiva que seja realizado os processos necessários para a avaliação e manutenção bucal, trazendo-Ihes malefícios a saúde. 


\section{CONGQEESSOCIENCIAESOCIEDADE

Outro fator que prejudica o tratamento bucal eficaz, é o oferecimento de alimentos à base de açúcar, pelos responsáveis, como forma de tranqulizá-los.Dessa forma, há o maior crescimento de cáries e doença periodontal em uma área onde já não existe a limpeza adequada.

Além disso, encontra-se uma enorme relutância por parte dos profissionais na maneira de como abordar e dar adesão ao tratamento dos pacientes deficientes cognitivos, muitos não possuem conhecimento adequado, e não dão a devida importância para o assunto. Aliado a isso, ainda existe a apreensão dos pais, a baixa prioridade nos serviços de atendimento, as dificuldades da rotina diária, a distância e a falta de transporte adequado.

Todas essas adversidades influenciaram de maneira significativa o processo de coleta, já que inicialmente foram propostas 30 amostras e só foram possíveis a captação de 3 até o momento. É importante ressaltar que por maiores que sejam os desafios optou-se por dar continuidade à pesquisa formulando a estratégia de um mutirão com o objetivo de recuperar as amostras que não puderam ser coletadas.

Acredita-se na importância da aplicação do teste de $\mathrm{MN}$ uma vez que possibilita o diagnóstico precoce e a adesão a um possível tratamento e cuidados específicos, o que traria inúmeros benefícios a vida desses pacientes, destacando-se melhorias em seus prognósticos e incluindo-os em serviços de atendimento à saúde de mais qualidade e eficiência.

\section{CONSIDERAÇÕES FINAIS}

Ao concluir a pesquisa será possível ampliar as publicações sobre o assunto e trazer benefícios aos pacientes, pois a partir dos dados coletados gerará formas para uma análise dos fatores de riscos associados à instabilidade cromossômica de micronúcleos e células basais da mucosa bucal, em pacientes com deficiência cognitiva, contribuindo para as publicações de temas referentes a patologias, proporcionando informações bem fundamentadas em relação ao tema, estimulando a pesquisa em saúde entre os mais diversos estudantes e profissionais da saúde, de modo a contribuir com aprimoramento das medidas de prevenção.

\section{REFERÊNCIAS}

ANDERS, PL; DAVIS, EL. Oral health of patients intellectual disabilities: a systematic review. Spec Care Dent. 2010. 


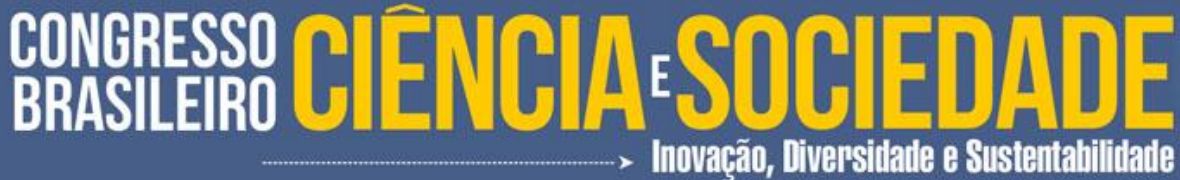

CARRANO, A V, NATARAJAN, A T. InternationalCommission for ProtectionAgainst Environmental MutagensandCarcinogens. ICPEMC publication no.14. Considerations for population monitoring using cytogenetic techniques. MutationResearch, v.204, p.379-406. 1988.

FERREIRA, Aurélio Buarque de Holanda. Dicionário da língua portuguesa. 5. ed. Curitiba: Positivo, 2010.

FREITA, Valéria Souza et al. Efeitos genotóxicos de fatores considerados de risco para o câncer bucal. Revista Baiana de Saúde Pública, v. 29, n. 2, p. 189, 2014.

GURIAN, M.B.F; OLIVEIRA, R.C; LAPREGA, M.R; RODRIGUES, Júnior A.L. Rastreamento da função cognitiva de idosos não institucionalizados. Rev Bras Geriatr Gerontol. 2012

HERRERA, E.M; LOPEZ, A.D.A; OSORIO, D.AP. Cognitive functionality of elderly residents in social protection centers in Cartagena. Indian J App Res. 2015

Idaira Y, Nomura Y, Tamaki Y, Katsumura S, Kodama S, Kurata K, Asada Y. Factors affecting the oral condition of patients with severe motor and intellectual disabilities. Oral Dis. 2008.

O'KEEFE, E. Oral health of patients with intellectual disabilities. Evid Based Dent. 2010.

OLIVEIRA, A.C; CZERESNIA, D; PAIVA, S.M; CAMPOS, M.R; FERREIRA, E.F; Utilization of oral health care for Down syndrome patients. Rev Saude Publica. 2008.

Rapalo DM, Davis JL, Burtner P, Bouldin ED. Cost as a barrier to dental care among people with disabilities: a report from the Florida behavioral risk factor surveillance system. Spec Care Dent. 2010.

THOMAS, P. et al. Buccal micronucleus cytome assay. Nat Protoc. v. 4, n. 6, p. 825-837, may. 2009.

UCHÔA, S. let.al. Determinação da instabilidade cromossômica e morte celular em células da mucosa bucal em pacientes com deficiência cognitiva. 2019. 20 p. Projeto (Graduando em Enfermagem) - Centro Universitário Santo Agostinho. Teresina: UNIFSA. 2019. 